\title{
Analysis of Service Recovery Failure: From Minority Perspective
}

\author{
Yasemin Öcal Atınça
}

\begin{abstract}
We investigate the service failures towards diverse customer groups for the purpose to bring insightful proposals to the managers to recover from these failures. Previous literature provided insights regarding the perception of service failures by minorities and the challenge of recovery due to racial implications driven from the failure, however lacked to propose suggestions for the managers so that they can take either corrective steps toward service failure recovery or prevent service failure through an effective training program. In this conceptual paper, we propose that, when the service provider and the customer are from different races, and the customer experiences a service failure, without the understanding of the process, service recovery is very hard to achieve. Race is an important factor in intention to bring the customer back for repurchase. The main contribution of this research is adding the race factor and the understanding of the service process into the model.
\end{abstract}

Keywords: Service Failure, Service Recovery, Consumer Behavior, Minority Marketing, Race difference

JEL Classification: M10, M30

\section{Introduction}

Marketing literature has been revolving around the consumer for the past decade. Finding the perfect fit between the service provider and the customer together with increasing emphasis on diversity has been a challenge. Adapting to the reality of diverse business environment required restructuring. In order to customize their services for the diverse consumer groups, firms have been spending billions of dollars for recruiting and training the workforce for the market. However, literature has not emphasized the diversity issue enough in order to lead the way for executives in the market place.

The literature in general has recognized the value in customer and market orientation. Organizations are constantly learning to adapt to the market that they are operating in. When the organization is able to function the way that fits in with the expectations of the market, they benefit from this. The key in adapting towards the needs and wants of customers is all about finding out the expectations of them. Service failure literature has investigated this issue deeply. Customer's expectations have a great impact on how they perceive the service received by the service provider. For instance, Bolton and Mattila (2015), reports that warmth in communal relationships between the customer and the failed service provider is needed for rapid service recovery. According to the authors, how customers perceive the company, even in areas not directly related to consumer-buyer relationships, such as corporate social responsibility, shapes customers' perceptions and in return their willingness forgive in case of a service failure. 
The strategy literature talks about the advantages of early entrants and how when under certain circumstances, late entrants can also be successful in the same market despite all the advantages of the early entrants (Varadarajan et al., 2008). The main reason for their success remains to be able to adapt and offer a cost efficient product that serves the same function with the competitor, in other words creating a competitive advantage. A competitive advantage can truly serve its purpose when it is hard to imitate and it serves as a differential advantage that is appealing to the target market.

Customer expectations change based on both the market and the quality and the type of service that the firm offers. Even though the goods and services offered may be similar, the expectations of the customers may be different. In a service failure situation, the recovery expectations of customers also vary based even when the goods and services are very similar. The reason for this is because of cultural differences between the customer and the service provider. Therefore the service provider should be aware of the varying service recovery expectations and adapt to these in order to gain the customer for a returned purchase (Ringberg et al., 2007).

Service recovery literature has long found evidence that when customers experience a series of service failures and recovery attempts, their perception changes based on the most recent recovery attempt. The repurchase intent of the customers increases when they experience satisfactory recovery attempts. A study has tested the impacts when customers experience two service failures. The findings indicate that, when customers experience a satisfactory recovery effect after an unsatisfactory recovery effect the recent experience is the one remembered in future purchasing decisions (Maxham and Netemeyer, 2002). In addition, after a service failure, when poor service recoveries are present, this creates a double deviation effect and has a compounding effect on the already low customer evaluations (Maxham and Netemeyer, 2002).

Experiencing a service failure with a recognized brand also changes the perceptions of the customers toward the service failure. Roehm et al. (2007) indicated that when the responses or recovery attempts are timed immediately after the failure, high equity brands fare the best. However when this is not the case, high equity brand evaluations appear to be affected even worse. Brady et al. (2008) examines the role of brand equity as a strategy that offsets the negative effects of a performance failure. Brand equity effect can be defined as a prevailing advantage that spans the entire failure and recovery sequence. Another study also supports the fact that service quality and organizational commitment have direct effects on customer service recovery expectations (Kelley and Davis, 1994). The variation in customer response is also affected by the cultural background or emotional state of the customer. The literature suggests that in order to increase the satisfaction, managers need to increase their understanding of the complexity of customer emotions and the role of emotions in customer's responses to service failure and recovery encounters (Smith and Bolton, 2002). The study provides important insights for managers regarding how they should fit the recovery efforts to the emotional state of the customer and train their employees in that sense. In addition to the emotional state of the customers, for the purpose of finding the correct fit in service recovery efforts, the impact of culture needs to be recognized. A study regarding this issue revealed that, cultural differences impact the attributions of customers towards service failures and moderate their satisfaction with the service recovery process (Mattila and Patterson, 2004).

Mainly the efforts of marketing scholars in service recovery context is based on the fact that firms are pressured more than ever to provide the best customer service to their target groups. Also the literature has long ago evidenced that the service failures and failed recoveries are a leading cause of customer switching behavior in service organizations. Well-executed service recoveries are important for enhancing customer satisfaction, building customer relationships, and preventing customer defections (Smith et al., 1999).

Marketing literature has moved from goods oriented markets to service oriented markets (Vargo and Lusch, 2008). Therefore service recovery concept's importance has greatly increased. However, service recovery has still not been defined as well in the literature. Compensating customers is a common service recovery strategy that mitigates the anger and the disappointment of the customer (Grewal et al., 2008). 
Social comparison besides compensation also reduces anger and improves post-purchase intentions (Bonifield and Cole, 2008).

It is important to understand how consumers process service failures regardless of the recovery outcome because a good majority of the customers do not report their complaints to the firm. It is essential for the service provider to understand the service quality expectations on customer reactions to service failures regardless of the recovery outcome, since these failures may never be reported by the customers. Findings indicate that customer react quite negatively when they believe that the service failure could have easily avoided by the firm (Choi and Mattila, 2008). This also depends on the relationship of the customer with the firm. The relationship between the customer and the company is believed to shape the attributions and expectations of the customers when the service failure occurs. The empirical evidence shows that, customers with higher expectations of relationship continuity had lower service recovery expectations after service failure. This indicates that, relationships buffer service organizations when service failure occurs (Hess et al., 2003). Thus, relationship marketing appears to be a key concept in resolving issues as such and becomes a cure for many concepts dealing with customers. Based on this general discussion we now move on to the theoretical development part.

\section{Theoretical Development}

Our model is depicted on Figure 1. On this model we propose service failure leading to lower intention to repurchase and service recovery through lower customer satisfaction, firm loyalty and product loyalty. We also propose potential moderating effect on race difference and understanding the service process. We start with explaining our rationale for the main effect relationships between service failure and customer satisfaction, firm loyalty and product loyalty. We move on by explaining the relationship between these three variables and two outcome variables, intention to repurchase and service recovery. We continue with explaining our proposed moderation effect.

Figure 1

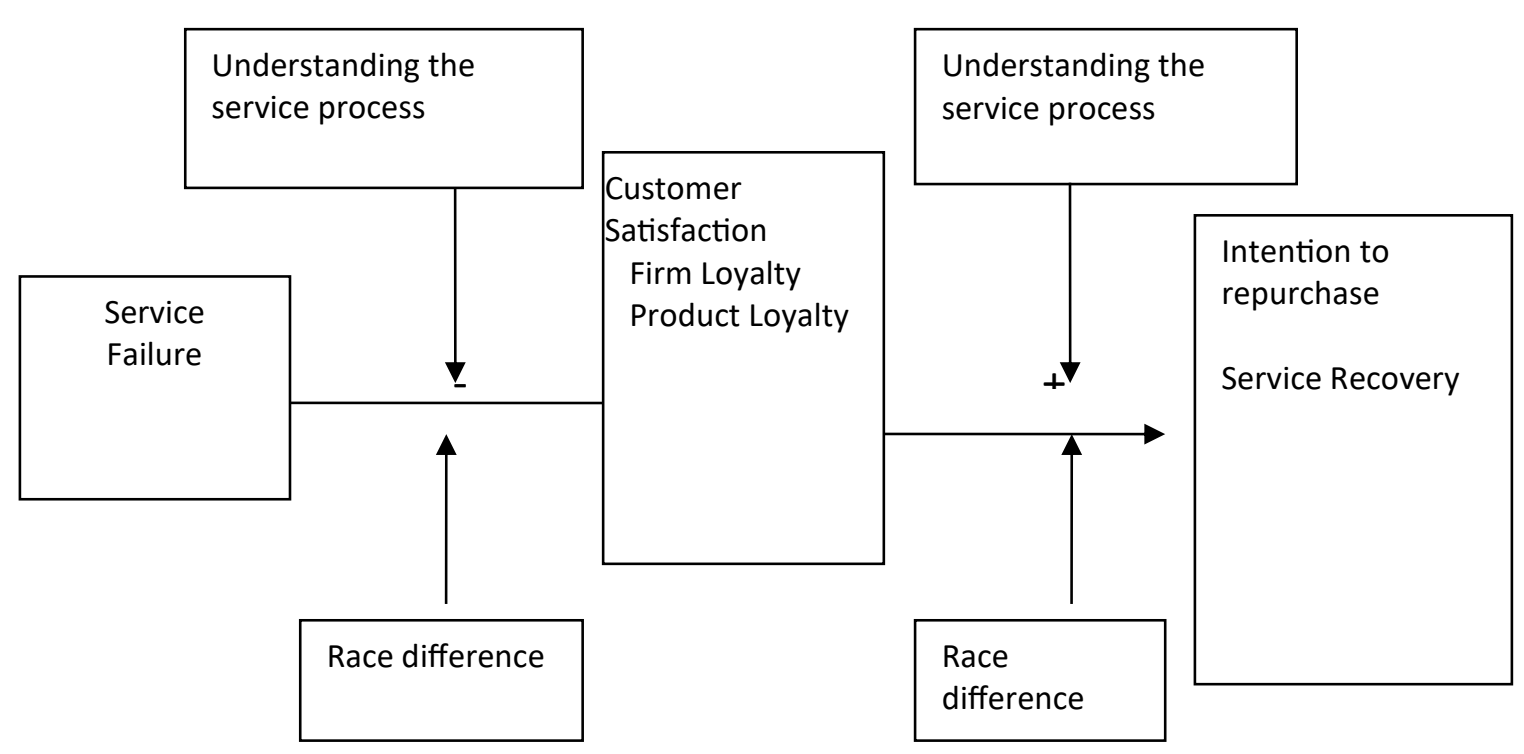

When customers experience a service failure, there is a serious effect on customer satisfaction, firm loyalty and product loyalty. Equity theory (Adams, 1965) indicates that, the relationship between the input and the output should have certain proportion that is satisfying enough for the investment maker, in this case the customer. Therefore when the customer invests in the business by being a loyal customer with minimum intentions of switching, they expect to receive a high performance service. If the service provider cannot provide the service that the customer is seeking for ( the perfect fit), this can well be perceived as a failure by the customer group and decrease the customer satisfaction, firm and product loyalty and 
repurchase intentions of the target group. As stated in the literature, customer's emotional state, cultural background, loyalty, intention to repurchase the firm's product or service has an impact on customer's perception of firm's service failure and whether or not the recovery is satisfactory to the customer. Basically the desire to continue the relationship (Moorman, et al., 1992) decreases on the customer side and it becomes harder to win back the customer yielding to harder recovery from this dissatisfactory experience (Hunt and Morgan, 1994).

We propose that;

Proposition 1: Service failure is negatively related to customer satisfaction

Proposition 2: Service failure is negatively related to firm loyalty

Proposition 3: Service failure is negatively related to product loyalty

Firm loyalty, product loyalty and customer satisfaction affects the intention to repurchase and whether or not the customer can be satisfied with the service recovery offered by the service provider. Intention to repurchase is a significant concept in marketing literature. The main reason for that is we look for ways to execute an effective strategy that will differentiate us from our competitors in the market. This can be done by implementing relationship marketing, where we build a relationship with our customers so that the relationship does not end after the first purchase. In building this relationship, marketers try their best to persuade the customers in coming back for returned purchases. Based on this logic, it is essential for marketers, to find effective strategies in bringing the customer back to the business. Based on the social status, age, education and other characteristics of the potential market, we need to find ways to attract customers back to the business. As stated above, from the emotional state of the customer to their cultural background, we want to develop commitment and loyalty towards the business by fitting the products and services offered to the liking of the customers. As a result we expect the customers to desire to maintain this valued relationship and in order for them to value; they must trust that the firm will deliver the high quality service expected by the customer. The most recent literature has investigated the impacts of delivering high quality service and perceived value to satisfaction, corporate image and behavioral intentions (Hu et. al., 2009). We can conclude that achieving high quality service and creating superior customer will ultimately bring in satisfaction and this will lead to retaining our customers (Hu et. al., 2009). Another recent study has revealed that, the quality of the service and the customer's perceived value and image and influenced satisfaction is also a determinant of loyalty (Lai et al., 2009). Customer's intention to repurchase is impacted by satisfaction and perceived value (Dongjin, et al., 2008). In strategy literature, we find that switching costs mediate the perceived value and satisfaction. That potential mediating affect is beyond the scope of this study so we propose;

Proposition 4: Customer loyalty is positively related to intention to repurchase.

Firm loyalty and product loyalty may be hand in hand depending on the strategy that the firm is adapting. As mentioned previously, sales person knowledge and treatment to the customer does have a significant impact in perceptions of the customers towards the business. Therefore, these concepts also impact the repurchase intention of the customer. Obviously both firm and product loyalty brings intentions of repurchasing. When the customer is loyal to the firm, he/she is making every effort to maintain this relation by making repeated purchases. As mentioned previously, switching costs also have significance in the level of the desire of customer to continue the relationship (Moorman et al., 1992). Gaining trust is the key to achieve loyalty (Reichheld and Schefter, 2000; Alhabeeb, 2005). The variety of the services and products offered by the firm, the attitudes of the employees, the quality of the product and service and its present strategy has a significant impact on the loyalty intentions of the customer. Once this fit is created, customer loyalty increases and this results in increased intention to repurchase. Based on this we propose that;

Proposition 5: Firm loyalty is positively related to intention to repurchase.

Product loyalty also starts with the tendency to move the customer towards making another purchase of that same product because of increased levels of satisfaction from the previous purchase. 
Although recent literature focuses on the fact that, building relationship with the customer can be as effective as the features and quality of the product in achieving customer satisfaction, Jacoby and Keyner (1973) argue about brand loyalty being related to repeated purchase behaviors. Although, in general they argue that brand loyalty is one form of repeated purchase behaviors and it certainly has other forms, the marketing literature both posits them as psychological behaviors. Jacoby and Keyner (1973) fail to make the distinction between brand loyalty and repeated purchases. In addition, the literature has defined brand loyalty as the percent of repeated purchases made towards the same brand (Lawrence, 1975). The concept of loyalty stays the same whether for product, the firm or the brand. Establishing trust can be defined as winning the customer by offering the quality of service or the product, the variety at the time that the customer desires. Once this is established, the customer will most likely come back for a returned purchase. In other words, once we reach the level of ultimate satisfaction, and once the customer perceives value in the relationship, we will win the customer for a returned purchase and the intentions of repurchase will increase. Intentions and the actual outcomes are different constructs in the literature. However, we can conclude that as the psychological arousal to purchase increases the actual behavior will happen. Based on this discussion we propose that;

Proposition 6: Product loyalty and intention to repurchase are positively related.

As mentioned previously, once a service failure occurs, the efforts to correct the failure and win the customer or in other words service recovery becomes a challenging concept. Hwang, et al. (2016) explains the importance of providing service justice to the customer. According to the authors, service justice is divided into procedural justice, such as the process with regard to refund policies, distributive justice, which is about the final outcome, and finally interactional justice, which focuses on the quality of interaction between the customer and the service representative. Among them, interactional justice is observed to be the biggest determinant of recovery from service failure. If in fact, the service provider fails to provide service justice, the customer gets even more dissatisfied. Customer's perception of the firm, the service or the product may be damaged because of this unsatisfactory experience. Service recovery expectations of the customer also vary based on customer's trust and the perceived image of the firm and the product offered. If the customer believes that the failure could have been avoided easily, the recovery expectations naturally go up and customer satisfaction is impacted positively. In other words the customer believes that company is willing to fix its mistake if he or she is satisfied with a previous experience. Customer loyalty towards the firm and the product may be a forgiving mechanism to accept the recovery efforts of the firm as well. When a well known product of a high quality brand fails, customers think that the company will be more willing to fix this problem. Sengupta et al. (2015) reports the effect of brand recognition on the relationship between service failure and coping strategies. Also the strategy literature tells us that the impact of switching costs do play role in customer's perception towards the service recovery efforts of the firm. Customers do not like to change their brands that easily if the switching cost is high. Based on this discussion we propose that;

Proposition 7: Customer satisfaction is positively related to service recovery.

Proposition 8: Firm Loyalty is positively related to service recovery.

Proposition 9: Product loyalty is positively related to service recovery.

\section{Proposed Moderating Effects}

The literature has mainly investigated the impact of race in advertising. The impact of race in service failures still needs a lot of investigation. Since black consumers now make up an important and potentially profitable market, they are an important group that needs further investigation in order to be reached out by marketers (Simpson et al., 2000). The advertising literature found out that when the race of models used in advertising campaigns matched the race of the potential customers, the media effects have been maximal. However, when rating perceived effects on self, whereas blacks identified strongly with black models, there was no significant difference in the way whites identified with fashion models of either way (David et al., 2002). Based on social distance and social identification theories, there are no significant differences between the two groups on perceived effect on self especially, when the race of the models matched the race of the potential customers. On the contrary, when the race of the model and the customer was different, blacks 
tend to be more withdrawn, or they perceived black models to be more attractive. Whites however, thought that black models were more attractive than whites. This indicates that the norm of beauty in advertising is different (David et al., 2002).

Another study proposed that, as blacks move up the socio economic ladder, they tend to have similar attitudes towards advertisements (William and Qualls, 1989). This study can also be shown as an evidence to the fact that customer's socio-economic condition, as well as culture and emotional state is also affected by this change and their perception changes over time with these changes (William and Qualls, 1989). In support of this, the study of Simpson et al., (2000) investigates the affect of perceived homophily and proposes that the expressed level of perceived similarity will have direct effect on the purchase intent for the product which the advertisement is promoting. It has been over 30 years since black actors started to appear in commercials. The studies from those years revealed that, when a black actor appeared in the commercial, black consumers both tend to remember the product more easily and also have more positive affect towards the product (Simpson et al., 2000). Research also found that, when consumers perceive similarity between the sales person and themselves, they are more likely to make a purchase (Simpson et al., 2000). The same issue has been tested in sales literature and some food companies found that, minority sales people are more effective than white sales people in minority neighborhoods, in retail stores (Churchill et al., 1988). Although there are no set characteristics, mental abilities or personality traits in measuring the sales aptitude and performance, in retailing it is wiser for sales managers to hire sales people with similar characteristics with their potential customers (Churchill et al., 1988). Another study suggests that, hiring sales people with similar characteristics is not the only reason for success, there should also be emphasis on the performance of the salesperson. However, we want to put forth that race has different implications on this issue. When salesperson customer similarity is tested against the experience of the salesperson, the results have shown that, similarity was more important than experience in persuading the customers to buy both higher or lower priced items. When the salesperson emphasized the fact that he/she has consumed similar or the same items, it influenced customers more than the expertise of the salesperson (Woodside and Davenport, 1974). With the recent focus on relationship marketing emphasizing similarity of the salesperson and customer, developing a relationship is the differential competitive advantage that is hard to imitate and has financial rewards as well.

A study in retailing has investigated the customer responses to interactional service recoveries and found that, employees who interact badly with customers have an impact on the satisfaction about the organization (Hess et al., 2007). However, when those customers understand that the problem they have experienced is not specific to the organization and could not be controlled easily by the organization, their dissatisfaction decreases (Hess et al., 2007). Based on this, we can conclude that customer's perception and understanding of the reasons of the failure have an impact on their satisfaction towards the service provider. Another study has found that, when a service failure is experienced, discrimination is an important factor in evaluating that service failure and thus blacks evaluate the service provider more harshly than the white customers. Especially, in a setting where there are no black customers available, when a black customer experiences a service failure, he or she evaluates the situation more severely and it is much harder to recover the failure (Baker et al., 2008).

These findings suggest that if black customers could understand the process of the service delivered, they might have a better understanding of why this failure has occurred. Since previous research has proved that, when customers understand that problem is not specific to the company and may be hard to control, in other words it was not the service provider's fault, they might not evaluate the service provider as that severely. Therefore, we can suggest that if the customer understands why there has been a failure or why the service has not been delivered in the way that customer is expected to, the customers might end up recovering more easily.

In addition, it will be easier to win these customers back after a service failure, once they understand the service process. When the service process is complex, and the customer experiences a delay in the service, they might not understand the reason for that delay. In addition if the service provider and the customer are from different races, black customer will most likely draw the conclusion that this unsatisfactory experience is due to a racial factor. For that reason, it will be harder for that customer to recover from that 
experience and as a result, this failure behind that service, their intention to repurchase will decrease because of this break in the pipeline. However, when they understand the process behind that service, they will most likely have a better evaluation of the service provider and will not conclude this as discrimination so the recovery tools will be much more effective and these customers will come back for purchases. Their loyalty to the firm and the product or the service will also not be affected as much when they can reach a logical conclusion about the failure experienced.

Based on these findings in the literature, we propose a moderating effect of race on the relationship of service failure and customer satisfaction, firm loyalty, and product loyalty, such that when the customer is from a minority race (black) and the service provider is white, these relationships get stronger. The negative effect of service failure is avoided if the customer understands the reason of the failure occurred. In complex services, it is harder for the customer to understand why this failure has occurred. If the customer has a hard time reasoning with the failure it is more likely that he/she will conclude this has occurred due to personal reasons. Gelbrich et al. (2016) proposes that the relationship quality and perceived reciprocity indirectly effects the service recovery and satisfaction relationship. When the service provider and the customer is from different races and the environmental setting does not include minority customer or employees, in the occurrence of an unsatisfactory service the minority customer is most likely to draw a racial reasoning out of this failure. This situation, in a way, diminishes the relationship quality and in return impacts the satisfaction and service recovery relationship. However if the customer can understand the reason behind the failure, it may be easier to satisfy and recover from this mainly because the customer will not associate this experience with race.

Baker et.al (2008), investigates the role of race and the discriminatory bias in a restaurant setting. When there are no black customers and the service provider is white, in the occurrence of a service failure, the black customer evaluates this failure more severely due to a perception of a discriminatory bias. Therefore, there should be strong moderation effect of race between service failure and customer satisfaction, firm loyalty and product loyalty. It may be even harder to win the black customer and recover from the service failure than the white customer. Relative to white customers, the most common efforts of service recovery such as; coupons, gifts and apology is found to be not as effective in black customers when they perceive discrimination. Equity theory (Adams, 1965) posits that the outcome received should have a certain ratio with the input given in the relationship. Black customers in such cases perceive the outcome ratio to be unsatisfactory and do not want to be involved in this relationship. Therefore customer satisfaction, firm and product loyalty decreases more strongly compared to white customers (Baker et al., 2008). Another study evaluated the effects of customer participation in co-created service recovery. Apparently, when customers take a major role in the service recovery process, they are more likely to accept the recovery and tend to report higher levels of satisfaction with the service recovery and higher perceived value (Dong et al., 2008).

Our proposition of the moderating effect of understanding the service recovery process is based on the fact that if the customer feels that he/she plays a role in the service process and understands why there has been a failure, there will be increased level of satisfaction, firm and product loyalty, intention to repurchase and the service recovery will be more successful. A recent meta-analytic study (Vaerenberg et al., 2014) recommend that the companies should approach the customer before negative attributes built using fast and accurate communication. Hence, if the service failure is explained to the customer rapidly, which increases the likelihood of customer's understanding, the chance of recovery is likely to go up as well. The customer will not evaluate the service provider as harsh when he/she understands what went wrong and why. In processes that are complex for the customer, it is essential for service providers to give importance to this issue. A lens crafter for example has a complex service recovery process and hard for customers to understand why there has been a delay. In a context that the service provider is white and that there are not black customers in the setting, when a service failure occurs, it is very likely for the customer to have discriminatory bias when evaluating this failure. As a result, the evaluations of this customer will be much severe than a white customer. Therefore, race has a moderating effect. In general, the customer is very much unlikely to have knowledge about this process, however when the process is explained to the customer, 
this understanding will have a moderating effect and more than likely will strengthen the customer satisfaction, success of the service recovery, increase firm and product loyalty and intention to repurchase. Based on this discussion we can propose the following:

Proposition 10: Race difference moderates the relationship between service failure and customer satisfaction, firm loyalty and product loyalty such that the negative relationship gets stronger when the customer and service provider are from different races.

Proposition 11: Understanding the service process moderates the relationship between service failure and customer satisfaction, firm loyalty and product loyalty such that the negative relationship gets stronger when the customer fails to understand the service process.

Proposition 12: Race difference moderates the relationship of customer satisfaction, firm loyalty and product loyalty to repurchase intention and service recovery and such that the positive relationship gets stronger when the customer and service provider are from same races.

Proposition 13: Understanding the service process moderates the relationship of customer satisfaction, firm loyalty and product loyalty to repurchase intention and service recovery and such that the positive relationship gets stronger when the customer understands the service process.

\section{Conclusion}

As a future extension of the study on the proposed theoretical relationships, researchers may choose to utilize an experimental design technique to test the above model. A sample of customers from diverse backgrounds can be surveyed about their willingness to forgive in the case of understanding the reasons for service failure. In addition, match between the racial background of the seller and the buyer maybe worthy of exploring. Furthermore, the impact of the customer, the firm and the product loyalty on customer satisfaction, service recovery, and in return, intention to repurchase can be further explored by utilizing survey methodologies.

There is no doubt that the relationship between service failure, customer satisfaction, firm loyalty, product loyalty, intention to repurchase, and service recovery are important topics to be thoroughly analyzed. However, importance of race and understanding of the service process impact on these variables may be the biggest contribution of this study as the demographics of United States, and for that matter the World, is constantly changing. Shedding some light on the unknowns of our proposed model may contribute to the efforts of the marketers struggling to solve the puzzle about service recovery and repurchase intentions.

\section{References}

Adams, J.S. (1965). Inequity in social exchange. Adv. Exp. Soc. Psychol. 62:335-343.

Alhabeeb, M. (2005). Consumer Trust and Product Loyalty. Allied Academies International Conference. Academy of Marketing Studies. Proceedings, 10(1), 1-6.

Baker, T. L., Tracy, M., \& D., J. J. (2008). Individual differences in perceptions of service failure and recovery: the role of race and discriminatory bias. Journal of the Academy of Marketing Science, 36, 552-564.

Bolton, L. \& Matilla, A.S. (2015). How does corporate social responsibility affect consumer response to service failure in buyer-seller relationships? Journal of Retailing, 91(1), 140-153.

Bonifield, C., \& Cole, C. A. (2008). Better him than me: social comparison theory and service recovery. Journal of the Academy of Marketing Science , 36, 565-577.

Brady, M., Cronin, J., Fox, G., \& Roehm, M. (2008). Strategies to offset performance failures: The role of brand equity. Journal of Retailing, 84(2), 151-164.

Choi, S., \& Mattila, A. S. (2008). Perceived controllability or service expectations: influences on customer reactions following service failure. Journal of Business Research , 61 (1), 24-. 
Churchill, Gilbert A., Jr., Garda, Robert A., Hunt, Shelby D., \& Webster, Frederick E., Jr. (1988). Developing, Disseminating, and Utilizing Marketing Knowledge. Journal of Marketing, 52(4), 1.

David, P., Morrison, G., Johnson, M. \& Ross, F. (2002). Body image, race, and fashion models: Social distance and social identification in third-person effects. Communication Research, 29(3), 270-294.

Dong, B., Evans, K. R., \& Zou, S. (2008). The effects of customer participation in co-created service recovery. Journal of the Academy of Marketing Science, 36, 123-137.

Dongjin, L., Shenghui, A., \& Kai, Y. (2008). Exploring Chinese consumer repurchasing intention for services: An empirical investigation. Journal of Consumer Behavior, 7(6), 448.

Gelbrich, K., Gathke, J. \& Gregoire, Y. (2016). How a firm's best versus normal customers react to compensation after a service failure. Journal of Business Research, 69(10), 4331-4339.

Grewal, D., Anne, R. L., \& Tsiros, M. (2008). The Effect of Compensation on Repurchase Intentions in Service Recovery. Journal of Retailing , 84 (4), 424-.

Hess Jr., R. L., Ganesan, S., \& Klein, N. M. (2007). Interactional service failures in a pseudorelationship: The role of organizational attributions. Journal of Retailing , 83, 79-95.

Hess Jr., R. L., Ganesan, S., \& Klein, N. M. (2003). Service Failure and Recovery: The Impact of Relationship Factors on Customer Satisfaction. Journal of Academy of Marketing Science , 31, 12-145.

Hu, H., Kandampully, J., \& Juwaheer, T. (2009). Relationships and impacts of service quality, perceived value, customer satisfaction, and image: an empirical study. The Service Industries Journal, 29(2), 111.

Hwang, H.J., Kang, M.J. \& Youn, M.K. (2016). Experiential regret in service failure: The role of service justices. Journal of Transnational Management, 21(1), 3-11.

Jacoby, J. and Kyner, D.(1973). Brand Loyalty vs. Repeat Purchase Behavior. Journal of Marketing Research, 10, 1-9.

Kelley, S. W., \& Davis, M. A. (1994). Antecedents to Customer Expectations for Service Recovery. Journal of the Academy of Marketing Science, 22 (1), 52-61.

Lai, F., Griffin, M., \& Babin, B. (2009). How quality, value, image, and satisfaction create loyalty at a Chinese telecom. Journal of Business Research, 62(10), 980.

Lawrence, T. Sr. (1975). Brand loyalty revisited: A commentary. JMR, Journal of Marketing Research (pre1986), 12(4), 488.

Mattila, A. S., \& Patterson, P. G. (2004). The Impact of culture on consumers' perception of service recovery efforts. Journal of Retailing , 80 (3), 196-.

Maxham III, J. G., \& Netemeyer, R. G. (2002). Journal of Marketing. A Longitudinal Study of Complaining Customers' Evaluations of Multiple Service Failures and Recovery Efforts, 66, 57-71.

Moorman, C., Zaltman, G., \& Deshpande, R. (1992). Relationships Between Providers and Users of Market Research: The Dynamics of Trust Within and Between Organizations. Journal of Marketing Research, 29(3), 314.

Morgan, R. M., \& Hunt, S. D. (1994). The Commitment-Trust Theory of Relationship Marketing. Journal of Marketing , 58 (3), 20-38.

Reichheld, F. \& Schefter, P. (2000). E-loyalty: Your secret weapon on the Web. Harvard Business Review, 78(4), $105-113$.

Ringberg, T., Odekerken-Schroder, G., \& Christensen, G. L. (2007). A Cultural Models Approach to Service Recovery. Journal of Marketing , 71 (3), 194-214.

Roehm, M. L., \& Brady, M. K. (2007). Consumer Responses to Performance Failures by High- Equity Brands. Journal of Consumer Research, 34.

Sengupta, A.S., Balaji, M.S. \& Kirshnan, B. (2015). How customers cope with service failure? A study of brand reputation and customer satisfaction. Journal of Business Research, 68(3), 665-674.

Simpson, E., Snuggs, T., Christiansen, T., \& Simples, K. (2000). Race, homophily, and purchase intentions and the black consumer. Psychology \& Marketing, 17(10), 877-889.

Smith, A. K. \& Bolton, R. N. (2002). The Effect of Customers' Emotional Responses to Services Failures on Their Recovery Effort Evaluations and Satisfaction Judgments. Journal of the Academy of Marketing Science, 30 (1), 5-23.

Smith, A. K., Bolton Ruth, N., \& Wagner, J. (1999). A Model of Customer Satisfaction with Service Encounters Involving Failure and Recovery. Journal of Marketing Research, 36, 356-372.

Vaerenberg, V.Y., Orsingher, C., Vermeir, I. \& Lariviere, B. (2014). A Meta-Analysis of Relationships Linking Service Failure Attributions to Customer Outcomes. Journal of Service Research, 17(4), 381-398. 
Varadarajan, R., Yadav, M., \& Shankar, V. (2008). First-mover advantage in an Internet-enabled market environment: conceptual framework and propositions. Academy of Marketing Science. Journal, 36(3), 293.

Vargo, S. L., \& Lusch, R. (2008). Service-dominant logic: continuing the evolutuion . Journal of Academy of Marketing Science, 36, 1-10.

Williams, J., \& Qualls, W. (1989). Middle-class black consumers and intensity of ethnic identification. Psychology and Marketing (6), 263-286.

Woodside, A., \& Davenport, J. (1974). The effect of salesman similarity and expertise on consumer purchasing behavior. Journal of Marketing Research (7), 151-175. 